\title{
RADIOACTIVE IODINE THERAPY IN THYROID DISORDERS
}

\author{
Alastair G. Macgregor, B.Sc., M.D., F.R.C.P.E., M.R.C.P. \\ Regius Professor of Materia Medica and Therapeutics, University of Aberdeen
}

Radioactive iodine (131I) has a part to play in the therapy of two thyroid disorders, carcinoma and thyrotoxicosis, by virtue of the selective concentration of it which occurs in functioning thyroid cells. The latter represent the only significant site of concentration of the iodide ion in the body, this occurring because of the necessity to incorporate iodine into the molecule of the thyroid: hormone thyroxine. "If, therefore, the gland is presented with ${ }^{131} \mathrm{I}$, a source of ionizing radiation is placed within the thyroid gland, and the physical properties of $131 \mathrm{I}$, the commonly used isotope, are such that there is little tissue irradiation except within the gland. The greater part of the biological effect of the radiation is due to the beta particles emitted by the source, and as these have only a range of a few millimetres in tissue, there is little appreciable effect elsewhere, unless, as in the treatment of thyroid carcinoma, the level of thyroid or tumour concentration is very. low and appreciable radiation effects occur elsewhere.

\section{Carcinoma of the Thyroid}

This, in absolute terms, is not a common condition, and it is a rare cause of death. In 1958, according to the Registrar-General's reports for England, Wales and Scotland, a total of only 386 persons died of thyroid carcinoma out of a total of $106,83 \mathrm{I}$ deaths from malignant disease $(0.3 \%)$ and out of a total of 589,908 deaths from all causes $(0.06 \%)$ in the United Kingdom. The treatment of thyroid carcinoma should be seen, therefore, with this background in perspective. Nevertheless, for the individual sufferer it can be most disabling. Consequently any hopeful therapy must be considered.

131 I can only be effective if the malignant cells are sufficiently differentiated to be able to concentrate ${ }^{131}$ I. Unfortunately, the more commonly encountered tumours are usually anaplastic and undifferentiated, and seldom can be induced to concentrate a worth-while amount of ${ }^{131} \mathrm{I}$. Most of the successfully treated cases of thyroid carcinoma are either follicular types of papillary adeno- carcinoma, or alternatively, are other types of well differentiated malignant adenoma. Prew dominantly papillary types of adenocarcinoma are seldom worth treating, but, in the experience of Pochin, ${ }^{13}$ treatment may be possible in some case of this category.

Nevertheless, radical surgery remains the first line of attack, however well differentiated the tumour, and isi I should be used to attack residua tumour growth and inaccessible metastatic deeo posits. Any persisting normal thyroid tissue wili concentrate ${ }^{131} \mathrm{I}$ preferentially to the tumour, and this normal tissue, if not surgically removed, ma have to be ablated by preliminary ${ }^{131}$ I therapy and a dose of the order of 80 millicuries is given for this purpose. Thereafter ${ }^{131}$ I concentration can be induced in some tumours under influence of the thyrotrophic hormone release from the pituitary because of the consequentia development of myxoedema. Pochin ${ }^{13}$ believe命 that, in histologically appropriate cases, concen trations of $0.1 \%$ of a test dose of ${ }^{131} \mathrm{I}$ per grant $\overrightarrow{\mathrm{B}}$ of estimated tumour mass may justify proceeding with therapy, and in that event repeated doses of roo-200 millicuries of ${ }^{131} \mathrm{I}$ are given. When suck treatment is successful glandular metastases ree solve, bony calcification can be induced, and pulmonary metastases disappear. In cases where worth-while concentration of ${ }^{131}$ I can be induced $d_{m}$. repeated testing with ${ }^{131}$ I should be carried ou甲 between therapeutic doses, and normally the amount concentrated in tumour tissue progres $\frac{}{5}$ sively diminishes. Any retained ${ }^{131}$ I can only be retained within thyroid tumour cells, and therap must be repeated so long as there is ${ }^{131}$ I retention

Pochin ${ }^{13}$ gives annual test doses of $10-25$ millitcuries four weeks after discontinuing thyroxing replacement therapy, and this is sufficient to allow detection of a tumour recurrence concen? trating only $0.01 \%$ of the dose. All patiento should receive thyroxine in replacement dose (0.2-0.3 mg. daily) when not receiving therapy, as any tendency to clinical hypothyroidism mat cause exacerbation of tumour growth.

Most clinics have had some spectacular succes 
in individual cases with ${ }^{131} \mathrm{I}$ - therapy, but it is not a form of treatment that, in the long-term view, has made much difference to the mortality and morbidity of this disease. Furthermore, the order of dosage necessary is very high and makes it essential that special facilities for handling doses, patients, and excreta be available in the centres where this form of therapy is practised.

\section{Thyrotoxicosis}

Thyrotoxicosis is a disorder for which there are three safe and generally applicable forms of treatment, and although each has its indications and possibly its own particular hazards, all are effective. The axiom that a plethora of therapeutic weapons implies an absence of therapeutic efficacy is, in this instance, shown to be untrue, and Greene ${ }^{6}$ and Riddell ${ }^{14}$ have outlined the role and scope of drugs and surgery in the management of the thyrotoxic patient.

Radioactive iodine (131I) is the newest of the three methods, but even so has now been employed for 20 years, and opinion throughout the world is becoming crystallized regarding its role. The frequency with which it is employed in any particular centre is governed by the criteria accepted as indications for treatment and a different emphasis is attached to these criteria at every hospital. Standards change with experience, and with the consequent reviews of the results, hazards and advantages of any form of treatment. In 1955 Myant and Pochin ${ }^{11}$ believed that with their methods of selection radioiodine would be found to be the treatment of choice for not more than $10 \%$ of all thyrotoxic patients. On the other hand, Macgregor ${ }^{9}$ found that of a total of I,034 cases of confirmed thyrotoxicosis referred to the Endocrine Clinic, Royal Infirmary, Edinburgh, during the years $1953-59$, no less than 621 , or $60 \%$, were regarded as suitable for ${ }^{131}$ I therapy. It is quite apparent, therefore, that there may be considerable variation in the extent to which this form of treatment is, in fact, used, and the availability of the procedure in a given geographical area is only one of the factors involved.

\section{Selection of Patients}

Treatment with ${ }^{131}$ I has very many advantages in terms of convenience and simplicity for patients and medical staff, immediate safety, absence from complications, and certainty of ultimate cure being achieved; the only unpredictable factors are the frequency of subsequent myxoedema, and the as-yet-unknown late effects of radiation. The incidence of myxoedema may be of the order of $5^{-15} \%$, but even higher figures have been acceptable to some American centres. In any case, it is for many patients easier and safer to keep them euthyroid with replacement thyroxine therapy, than to be forced to persevere with inadequate antithyroid treatment.

The question of the validity of the fears regarding late irradiation effects, in terms of thyroid carcinoma, leukaemia, and genetic effects, has been fully and fairly discussed recently by Blomfield et al., ${ }^{3}$ and their viewpoint undoubtedly expresses the consensus of opinion in this country and the United States: this is, that if ${ }^{131} \mathrm{I}$ therapy is restricted to adults, the danger of the subsequent development of a carcinoma of the thyroid is remote, that the reported incidence of leukaemia so far is no greater than that which would be expected in a population of the size of that which has been treated with 131I, and, lastly, that the contribution to any genetic hazard by the overall administered ${ }^{131} \mathrm{I}$ is very small. In the Sheffield region calculations show that the contribution of 131 I therapy for thyrotoxicosis to the genetically significant dose is approximately $0.3 \%$ of the natural background. This compares with a contribution made by diagnostic radiology estimated to be at least $22 \%$ of natural background. ${ }^{12}$

These factors govern the basic principles upon which case selection is based, but even so, the basic consideration is not whether late effects will be proven to arise, but whether, if they do arise, they arise with a frequency which makes ${ }^{131} I_{0}$ therapy unjustifiable. If after 20 years - and the answer will be available within the next few years - the incidence of carcinoma or leukaemia is of the order of only $0.1 \%$ of cases treated, and present indications are that it will be much less than this, then ${ }^{131}$ I therapy will be the treatment of choice. ${ }^{13}$ In many clinics this conclusion has already been reached, but in this country patients are not often treated. below the age of 45 unless other forms of treatment are impracticable, unduly hazardous or particularly inconvenient.

Macgregor ${ }^{9}$ has defined the categories acceptable for ${ }^{131}$ I therapy as:

(I) Patients over 45 , unless they have a sufficiently large and uncomfortable gland as to justify early surgery and quick mechanical relief and abolition of toxicity.

(2) Patients of any age with recurrent toxicity after previous partial thyroidectomy.

(3) Younger patients with associated disease which either itself determines life expectancy or appreciably increases the hazard of operation. This category includes those patients who do not remain in remission after antithyroid drug treatment and who are unsuitable for, or refuse, operation.

Applying these criteria, it was found that, of the first 500 cases treated, $10 \%$ only were below 


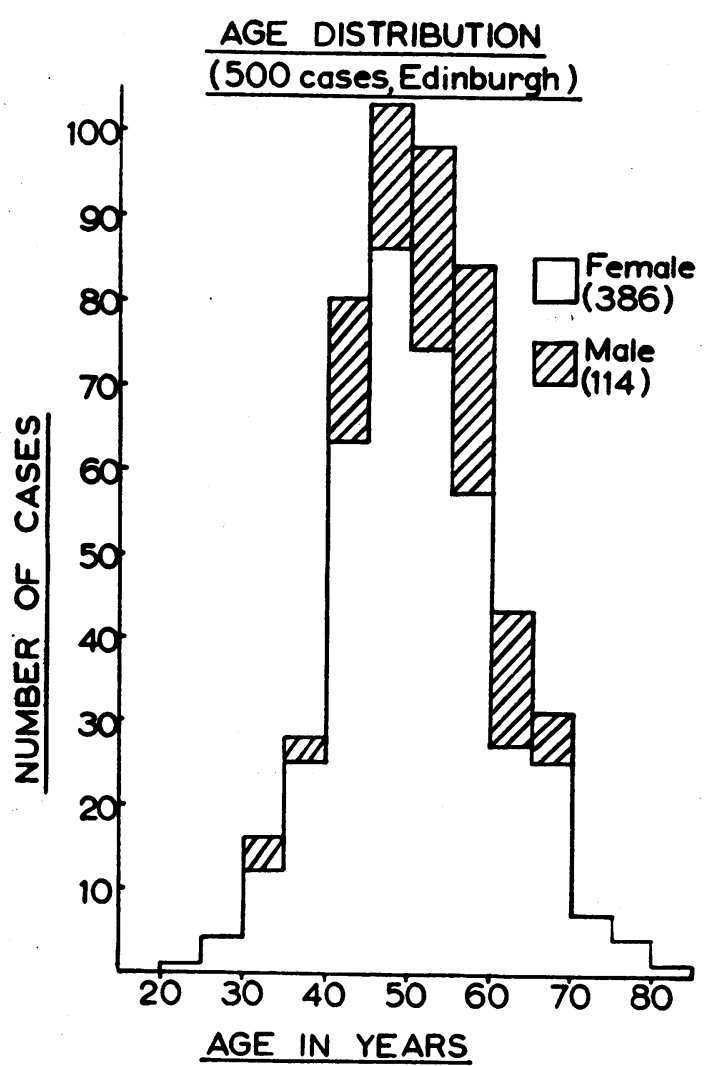

FIG. 1.-Age and sex incidence of 500 thyrotoxic patients treated with ${ }^{131} \mathrm{I}$.

the age of 40 , a further $16 \%$ lay between the ages of 40 and 45 , and $74 \%$ were 45 years of age or more (Fig. I): Of the 500 patients 53 had had a previous partial thyroidectomy, the majority of them being in the $26 \%$ of patients below the age of 45 years. It can be seen then that because thyrotoxicosis is now recognized as a disease which affects older people to a very much greater extent than was previously appreciated, it is inevitable that very many patients will qualify for 131I therapy if the currently recognized indications for treatment are accepted.

\section{Management of Patients}

The majority of thyrotoxic patients can safely be given ${ }^{131}$ I without any preliminary drug preparation, and this is in fact the usual procedure. It is essential that initial tracer measurements be made with ${ }^{131} \mathrm{I}$, not only to confirm the diagnosis and ensure that there is in fact thyroid gland avidity for the isotope, but also, in some clinics, to provide data upon which the size of the therapeutic dose is assessed.

If the patient has previously been receiving antithyroid drugs, these should be stopped three to seven days before the test or therapy dose, an ${ }^{n}$ need not be started again. It is exceptional to require to give iodides or antithyroid drugs aftero 131 I to combat continuing or recurrent toxicity,, but it is often convenient to render severely thyrotoxic patients euthyroid with drug treatment? before ${ }^{131}$ I therapy is contemplated. The responseto treatment may be slow and progressive, and i it is deemed unwise to allow severe toxicity to continue, even for a few weeks, it is much better 2 to give the patients antithyroid drugs for two ores three months before ${ }^{131}$ I therapy.

On the other hand, there is no proven virtue inroutine preliminary treatment with antithyroidw drugs, although this has been advocated by Frases et al. ${ }^{5}$ It would appear that pre-treatment witk methylthiouracil, at any rate, produces a radio resistant gland, ${ }^{16}$ and Crooks et al. ${ }^{4}$ found that the percentage of patients rendered euthyroid with a single dose of the isotope was significantly lower in a group of patients pre-treated with methylthiouracil $(29 \%)$, than it was in a group of patients who had had no previous drug therapy? $(75 \%)$. Nevertheless, in a study of 500 patients Blomfield et $a .^{3}{ }^{3}$ observed no consistent difference in response which could be attributed to previousdrug treatment. It would appear to be inherengy undesirable to use as a routine a procedure whin may require the use of unnecessarily large thea peutic doses of ${ }^{131} \mathrm{I}$.

Most patients can be treated on an outpatiento basis unless their general medical condition anकै severity of their toxicity justifies admission toळ hospital. After the preliminary testing, an ${ }_{5}$ dosage assessment, the 131 I dose is administered; and the patient is thereafter seen at lengthening intervals until the final response can be deter? mined.

\section{Assessment of Dosage}

The objective of therapy is to attain as early remission of symptoms as is consistent with क्? low probability of the induction of myxoedema. If a very large radiation dose is delivered, toxicity? will be quickly abolished, but eventual myxoedema is certain. Most workers aim to deliver to the. gland a dose of about 8,000 rads, although somen what lower dose intensities may be used for smal post-operative recurrences and appreciably large doses for patients with toxic nodular goitre. The procedure by which the millicurie dose for $\bar{Z}$ given patient is selected is one that varies at everye clinic, but the most important factor in deter mining the dose is the size of the thyroid gland? There are many potential errors inherent in any technique devised to determine thyroid glan size in the living subject, and a clinical assessmene 
reached by simple inspection and palpation is no more inaccurate than most of the refined techniques that involve scanning and mapping of the gland, or the intracervical injection of air. Blomfield et al. ${ }^{1,2,3}$ continue to use a formula relating many variables to the desired rad dosage, but Myant $^{10}$ and Macgregor $^{8}$ have fully discussed the factors which render invalid most of the assumptions on which are based this and similar formulae. Macgregor ${ }^{8}$ and Crooks et al. ${ }^{4}$ have shown that the results attained by a simple and clinical technique of dose prescription, dependent chiefly on an approximate clinical assessment of gland size, are in no respect different from those results achieved, as by Blomfield et al. ${ }^{3}$ by more complex and meticulous techniques. The usual order of millicurie dose used in the treatment of thyrotoxicosis ranges from about 4 millicuries for an impalpable gland to something of the order of 20 millicuries for the larger nodular glands. It is seldom necessary or desirable to give more than 20 millicuries at a single dose, and intermediate doses are determined by the size of the gland, the severity of the toxicity and the speed with which control is desired, for it may be that the need to obtain a rapid remission of symptoms is greater than the risk of the production of hypothyroidism. There is little doubt that individual variation in the degree of gland radiosensitivity outweighs in importance many of the other factors concerned in the response, and there is no inherent advantage to be gained by time-consuming and unnecessary preliminary investigations. Crooks and his colleagues showed, furthermore, that doses of ${ }^{131}$ I prescribed by the simple technique tended to be larger in the lower-dosage range and smaller in the higher-dosage range, than those which would have been prescribed had the formula for dose prescription been applied. Nevertheless, there was no evidence to show that, in individual cases where this occurred, these disparities had any effect at all upon the clinical results.

\section{Results of ${ }^{131}$ I Therapy}

Improvement progressively follows ${ }^{131}$ I therapy and in most centres about $60 \%$ of patients become euthyroid after a single dose of the isotope, three-quarters of such patients being normal within six months, and all being normal after a year. About $25 \%$ of patients require two or more doses of the isotope.

Larsson $^{7}$ demonstrated a maximal depression of thyroid function after 6-8 weeks, and transient hypothyroidism may develop at this time. Those patients who are going to become permanently hypothyroid have usually become so after six months, but although Macgregor ${ }^{9}$ found that
$12 \%$ of patients were hypothyroid after one yeafo a figure identical with that reported by Blomfiel $\$$ et al., ${ }^{3}$ the percentage had risen to $17 \%$ when the same group of patients was reviewed after $\mathbb{D}$ minimum period of three years. This late onsetof myxoedema is a feature of many series of treated cases, but need not occasion any anxiety as replacement therapy with thyroxine given to these patients is eminently satisfactory and safe and should be continued indefinitely.

Second and subsequent doses of ${ }^{131}$ I should no? usually be given until at least three months after the first or previous dose. It is difficult to devise practicable serial tests of thyroid function follow:ing ${ }^{131}$ I. therapy, although this is at present beinge attempted in some centres. Assessment of the need for further ${ }^{131} \mathrm{I}$ therapy is essentially a clinicaf decision, to be supported and confirmed by laboratory investigations, including, if possible, determination of the chemical serum protein $\triangleq$ bound iodine level. ${ }^{131} \Gamma$ tests are less helpful, but repeat therapy should be governed by considera tions similar to those affecting the original doses selection.

In addition to the disappearance of the manie festations of toxicity, the shrinkage of the thyroic gland can result in very considerable benefit: being gained by patients with a retrosternal goitge? tracheal deviation or narrowing, or with e gross and most unsightly visible goitres. Itồㅇํㅇ always a matter of considerable satisfaction patient and doctor if a scarless thyroidectomyo can thus be achieved in circumstances which previously would have demanded a dangerous and difficult operation with a knife.

Only rarely is it necessary to resort to surgery following ${ }^{131}$ I therapy, but Macgregor ${ }^{9}$ had to submit three patients out of 621 to partial thy roidectomy because of insufficient treatment and too slow a response after ${ }^{131} \mathrm{I}$. No patient is ever. totally resistant to ${ }^{131}$ I therapy, and the lack of an effective response reflects undue caution and conservatism in dose prescription.

Pregnancy has frequently followed successfuk ${ }^{131}$ I therapy, just as it often occurs when hyperthyroidism becomes controlled by any method? Because, however, of the ages of most of the patients treated, it does not occur more often, but no late sequelae are known to have occurred in the offspring of treated parents, and none can be anticipated. ${ }^{131}$ I therapy should never be given tow a patient known to be pregnant, because of the foetal concentration of ${ }^{131}$ I that occurs.

With respect to exophthalmos, ${ }^{131}$ I therapyes would appear to be very little different from operation or antithyroid drugs as a cause of $\mathrm{a}^{\mathrm{D}}$ worsening of the condition. Many patients' eyष्ठ signs improve markedly ${ }^{15}$ but in a number of 
instances ${ }^{131} \mathrm{I}$ therapy has been followed by an exacerbation of exophthalmos and ophthalmoplegia.

\section{Summạry}

We now have available in ${ }^{131}$ I an agent which is almost universally available, which is free of proven risk, which can be effective in all cases of thyrotoxicosis, and which can achieve results in many patients which would not be feasible with any other form of treatment. Its role in the treatment of thyroid cancer is very limited, but it may become the dominant therapeutic aid for the control of one of the commonest endocrine disorders, thyrotoxicosis.

\section{REFERENCES}

I. BLOMFIELD, G. W., JONES, J. C., MACGREGOR, A. G., MILLER, H., and WAYNE, E. J. (I951), Brit. med. Э.,' ii, 373 .
2. BLOMFIELD, G. W., JONES, J. C., MACGREGOR, A. G., MILLER, H., WAYNE, E. J., and WEETCH, R.S. (1955), Ibid., il, 1223 .

3. BLOMFIELD, G. W., ECKERT, H., FISHER, M., MILLER, H., MUNRO, D. S., and WILSON, G. M. (1959), Ibid., i, 63 .

4. CROOKS, J., BUCHANAN, W. W., WAYNE, E. J., and MACDONALD, E. (1960), Ibid., i, 151 .

5. FRASER, R., ABBATT, J. D., and STEWART, F. S. (1954), Brit. F. Radiol., 27, 23.

6. GREENE, R. (1960), Postgrad. med. F., 36, 468.

7. LARRSON, L. G. (1955), Acta radiol. (Stockh.), Supp. 126.

8. MACGREGOR, A. G. (1957), Brit. med. F., i, 492.

9. MACGREGOR, A. G. (1960), 'Memoirs of Society of Endocrinology,' No. 9 (in press).

10. MYANT, N. B. (1956), "Therapeutic Use of Artificial Radioisotopes,' p. 148. New York: John Wiley.

1 I. MYANT, N. B., and POCHIN, E. E. (1955), 'British Practice in Radiotherapy,' p. 382. London: Butterworth.

12. OSBORN, S. B., and SMITH, E. E. (1956), Lancet, i, 949.

13. POCHIN, E. E. (1958), 'Modern Trends in Endocrinology,' p. 46. London: Butterworth.

14. RIDDELL, V. (1960), Postgrad. med. F., 36, 447.

15. WAYNE, E. J., MACGREGOR, A. G., and BLOMFIELD, G. W. (1952), Brit. med. Bull., 8, 148.

16. WERNER, S. C. (1955), 'The Thyroid.' New York: Harper.

\section{NEWCASTLE SYMPOSIUM}

(Postgraduate Medical Journal, April 1960)

Price 6s. 6d. post free

THE THROMBOGENIC HYPOTHESIS AND

ITS IMPLICATIONS

J. B.-Duguid, M.D.

THE MANAGEMENT OF ACUTE RENAL FAILURE

Walter Elliott, M.B., B.S., Molly Hill, M.B., Ch.B., M.R.C.P., D.R.C.O.G., David N. S, Kerr, M.Sc., M.R.C.P., M.R.C.P.(Edin.), and Rosalind Ashcroft, Ph.D.

CURRENT RESEARCH IN MULTIPLE SCLEROSIS

E. J. Field, M.D., M.S., Ph.D., and Henry Miller, M.D., F.R.C.P.

THE SURGICAL TREATMENT OF PARKINSON'S DISEASE

John Hankinson, M.B.(Lond.), F.R.C.S.

CHRONIC OTITIS MEDIA

F. McGuckin, M.D., F.R.C.S.
SOME RECENT TRENDS AND DEVELOPMENTS IN DERMATOLOGY

G. Holti, M.D., and John T. Ingram, M.D., F.R.C.P.

SOCIAL AND ENVIRONMIENTAL FACTORS IN CHRONIC BRONCHITIS IN NEWCASTLE UPON TYNE

A. G. Ogilvie, M.D., F.R.C.P.

ENQUIRIES INTO MENTAL DISORDER IN OLD AGE

Martin Roth, M.D., F.R.C.P., and D. W. K. Kay, M.A., B.M., D.P.M.

STUDIES OF LUNG FUNCTION IN

\section{CHILDREN}

L. B. Strang, M.B., M.R.C.P., and S. D. M. Court, M.D., F.R.C.P., D.C.H.

EMBOLECTOMY IN THE LIMB ARTERIES

David J. Tibbs, M.C., M.S.(Lond.), F.R.C.S.

Published by

THE FELLOWSHIP OF POSTGRADUATE MEDICINE

60, Portland Place, London, W.1

References continued from page $435-$ A. W. Spence, M.A., M.D., F.R.C.P.

17. MCCARRISON, R., and MADHAVA, K. B. (1932). 'The Life Line of the Thyroid Gland,' p. 347. Calcutta: Thacker, Spink \& Co.

18. MARINE, D. (1924), Medicine, $3,453$.

18. MARINE, D. (1935), Ұ. Amer. med. Ass., ro4, 2334.

20. MARINE, D., BAUMANN, E. J., WEBSTER, B., and CIPRA, A. (1933), ₹. exp. Med., 57, 121.

21. MESSERLI. F. M. (1952), Gesundh. u. Wohlf., 32, $56 \mathrm{r}$.

21. MURRAY M. M. RYLE, I. SIMPSON , 3. W. WILSON, D. C.' (I948), Med. Res. Coun. Mem. No. 18. London: H.M.S.O.

23. SIGURJONSSON, J. (1940). ' Studies on the Human Thyroid in Iceland.' Reykjavik: Edda.
24. STANBURY, J. B., BROWNELL, G. L., RIGGS, D. S.,

PERINETTI, H.,' ITOIZ, J., and DEL CASTILLO, E. B.

(r954), 'Endemic Goitre.' Harvard University Monograph

in Medicine and Public Health, No. 12 . Cambridge, Mass.

25. TAYLOR, S. (1954), f. clin. Endocr., 14, 1412.

26. THOMPSON, J. (1933), Arch. Path., 16, 211.

27. Union of South Africa Department of Nutrition (1955),

Endemic Goitre in the Union of South Africa and Some

Neighbouring Territories.'

28. WEGELIN, C. (1928), Cancer Rev., 3, 297.

29. WILSON, D. C. (1941), Lancet, i, 21 I. 